\title{
BUDAYA ORGANISASI DAN KOMITMEN ORGANISASI PADA THE EMMERICK HOTEL SALATIGA
}

\author{
Manuela Ranske Halim ${ }^{1}$, Sutarto Wijono ${ }^{2}$ \\ Email:802016030@student.uksw.edu ${ }^{1}$ \\ Program Studi Psikologi, Fakultas Psikologi Universitas Kristen Satya Wacana ${ }^{1,2}$
}

\begin{abstract}
The purpose of this study is to determine the relationship between organizational culture and organizational commitment. The subjects of this study were employees of the Emmerick Hotel Salatiga. Determination of the subject was carried out with a saturated sampling technique, which consisted of 90 employees. Data collection techniques in this study used a quantitative method using a measuring tool. Data collection uses a psychological scale. The Original Commitment Scale developed by Allen \& Meyer (1990) and the scale developed from 7 organizational culture characteristics according to Robbins (2013) modified by Tazkia (2017). Analysis of the data in this study used descriptive analysis. Based on the analysis results obtained by 0.541 and known the significance level of $x$ and $y$ is smaller than $\alpha=0.05$. This means that the cultural variable with an organizational commitment of 54.1\%. The findings show there is a relationship between the cultural organization and organizational commitment.
\end{abstract}

Keywords: Cultural Organization; Organizational Commitment.

\begin{abstract}
Abstrak
Tujuan dari penelitian ini adalah untuk mengetahui adanya hubungan antara budaya organisasi dengan komitmen organisasi. Subjek dari penelitian ini adalah karyawan dari the Emmerick Hotel Salatiga. Penentuan subjek tersebut dilakukan dengan teknik sampling jenuh, yang terdiri dari 90 orang karyawan. Teknik pengumpulan data dalam penelitian ini adalah menggunakan metode kuantitatif dengan menggunakan alat ukur Pengumpulan data menggunakan yaitu skala psikologi Original Commitment Scale Items yang dikembangkan oleh Allen \& Meyer (1990) dan skala yang dikembangkan dari 7 karakteristik budaya organisasi menurut Robbins (2013) yang di modifikasi oleh Tazkia (2017). Analisis data dalam penelitian ini menggunakan analisis deskriptif. Berdasarkan hasil analisis didapat hasil sebesar 0,541 dan diketahui bahwa taraf signifikansi $x$ dan y lebih kecil dari $\alpha=0,05$. Hal ini berarti bahwa variabel budaya organisasi dengan komitmen organisasi sebesar, 54,1\%. Hasil temuan menunjukkan bahwa ada hubungan antara budaya organisasi dengan komitmen organisasi.
\end{abstract}

Kata kunci: Budaya Organisasi; Komitmen Organisasi.

\section{PENDAHULUAN}

Revolusi Industri 4.0 pada dasarnya mengakibatkan banyak perubahan termasuk cara manusia untuk berpikir, menjalankan hidup, dan berhubungan satu dengan yang lain. Era ini mendisrupsi berbagai aktivitas manusia dalam berbagai bidang terlepas dari bidang teknologi, diantaranya seperti politik, sosial, dan ekonomi (Prasetyo \& Trisyanti, 2018). Dalam memasuki revolusi industri 4.0, maka setiap perusahaan perlu memiliki persiapan untuk menghadapi perubahan. Persiapan yang perlu dilakukan untuk menghadapi perubahan tersebut perlu ditingkatkan secara integratif dalam segala sektor yang ada di perusahaan tesebut termasuk 
teknologi, perlatan, perlengkapan, networking dan sumber daya manusianya. Dalam bidang ekonomi, berbagai perusahaan yang tersebar di berbagai daerah di Indonesia memiliki berbagai macam variasi dalam mengembangkan usahanya ada yang berfokus diantaranya manifaktur, entertain, IT, dan juga jasa. Perusahaan yang berfokus pada bidang jasa salah satunya adalah hotel.

Salah satu hal yang perlu diperhatikan dalam menghadapi revolusi industri 4.0 yaitu karyawan dalam organisasi yang diharuskan mengembangkan diri secara profesional sebagai asset dalam melayani konsumen terutama untuk menghadapi perubahan revolusi industri 4.0. Seperti pernyataan yang diungkapkan oleh Khan \& Tuworski (2016) bahwa industri 4.0 adalah modernisasi industri yang dihasilkan dari penerapan teknologi canggih pada tahap produksi yang dapat menghasilkan peningkatan standar, layanan, fleksibilitas, dan kualitas bagi konsumen dan perusahaan untuk memenuhi persyaratan terbaru paradigma bisnis dan layanan. Dipertegas dengan ungkapan Emiroğlu et al (2015) yaitu salah satu faktor terpenting dalam keberhasilan industri pariwisata adalah karyawan dan daya saing organisasi pariwisata dan kelangsungan hidup mereka bergantung pada kualitas layanan yang mereka tawarkan. Sehingga penting untuk memperhatikan komitmen organisasi yang dimiliki karyawan. Menurut Mulyaningsih mengungkapkan komitmen yang tinggi dapat mendorong karyawan untuk bekerja dengan baik dan berusaha mencapai tujuan dari organisasinya.

Pada dasarnya, komitmen organisasi adalah kepercayaan individu pada nilai-nilai yang ada pada organisasinya, serta terlibatnya individu untuk kepentingan organisasinya dengan penuh usaha, dan loyalitas terhadap organisasi (ingin menjadi anggota tetap dalam organisasi) yang merupakan pernyataan dari karyawan pada organisasinya (Nurcahya, 2019). Tingginya komitmen organisasi yang dimiliki oleh karyawan dapat mempengaruhi kinerjanya menjadi lebih baik, begitu juga sebaliknya. Seperti penelitian yang dilakukan oleh Dwiyanti \& Abdilla (2018) bahwa karakteristik individu yang memiliki komitmen organisasi rendah adalah kurang memiliki komitmen terhadap perusahaan dan tidak bangga menjadi bagian dari perusahaan, kurang percaya pada perusahaan, dan merasa bahwa perusahaan tidak mendukung mereka. Karakteristik individu yang memiliki komitmen organisasi rendah, ditunjukkan oleh 
karyawan yang mengklaim bahwa mereka berkinerja rendah karena status pekerjaan permanen mereka tidak penting bagi mereka karena mereka mengklaim ada banyak perusahaan lain yang akan menerima dan mempekerjakan mereka. Dapat disimpulkan, rendahnya komitmen yang dimiliki oleh karyawan akan berdampak buruk bagi organisasinya.

Penulis melakukan observasi dan wawancara dengan 10 orang pada tanggal 25 Oktober 2019 yang berkaitan dengan komitmen organisasi. Dari hasil observasi dan wawancara tersebut, penulis menemukan bahwa ada 5 karyawan memiliki kesenangan dalam terlibatnya diri mereka terhadap kegiatan yang dilakukan di Hotel. Kemudian 2 karyawan yang lain mengakatakan jika mereka merasa takut jika keluar dari hotel akan kehilangan apa yang telah mereka investasikan. Lalu 3 karyawan mengeluh jika setiap kali mereka ingin keluar dari hotel, mereka memikirkan kewajiban yang ada dalam perkerjaannya sehingga memilih untuk tetap bertahan di Hotel. Dengan demikian dapat dikatakan bahwa ada masalah yang berkaitan dengan komitmen organisasi. Oleh karena itu, penelitian tentang komitmen organisasi penting untuk diteliti di hotel ini. Pernyataan tersebut didukung oleh hasil riset oleh Towers (2014) tentang komitmen organisasi yang menunjukkan bahwa $66 \%$ karyawan di Indonesia cenderung meninggalkan perusahaan tempatnya bekerja dalam kurun waktu 2 tahun, sementara hanya $34 \%$ yang menyatakan niat untuk tetap bertahan. Selain itu, dia mengatakan bahwa perusahaan di Indonesia harus meningkatkan komitmen organisasi pada karyawan mereka agar dapat memberikan pengaruh yang positif bagi perkembangan bisnis organisasinya.

Adapun faktor-faktor yang memengaruhi komitmen organisasi salah satunya yaitu budaya organisasi. Bedasarkan penelitian yang dilakukan oleh Situmorang (2014), faktor yang mempengaruhi komitmen organisasi adalah faktor kepemimpinan, komunikasi interpersonal, kepuasan kerja, dan budaya organisasi. Seperti pernyataan yang di ungkapkan oleh Edward (2016) bahwa sebagai suatu sistem asumsi, nilai, dan keyakinan bersama, budaya organisasi mengatur perilaku orang untuk berpakaian, bertindak, dan melakukan pekerjaan mereka untuk mencapai kesuksesan. Dalam hal ini, itu menunjukkan bahwa budaya organisasi adalah faktor terpenting dari pembentukan organisasi, dan faktor berkontribusi dalam penciptaan komitmen organisasi. 
Diperlukan pemahaman mengenai Budaya Organisasi untuk dapat meningkatkan komitmen organisasi yang dimiliki oleh karyawan. Secara singkat, Robbins (1996) menjelaskan bahwa budaya organisasi mampu membantu meningkatkan komitmen organisasi. Adanya budaya organ isasi yang dirasa cocok oleh para karyawan dapat membuat karayawan tersebut bekerja dengan maksimal, keterbukaan, kebersamaan dan kekeluargaan terhadap karyawan lainya dan juga terhadap organisasi yang ditempatinya. Kemudian Tazkia (2017) menyatakan bahwa Budaya Organisasi dapat menjamin hasil kerja dengan kualitas yang lebih baik, seperti membuka seluruh jaringan komunikasi, keterbukaan, kebersamaan, kegotongroyongan, kekeluargaan, menemukan masalah dan cepat memperbaiki, cepat menyesuaikan diri dengan perkembangan yang terjadi di luar. Pada The Emmerick Hotel Salatiga, karyawan memiliki pandangan yang selaras dengan salah satu budaya organisasi yang ada yaitu, bersatu untuk melakukan kegiatan yang berhubungan dengan kegiatan hotel seperti gotong royong dalam bekerja dan saling membantu sesama karyawan. Diperkuat dengan pernyataan oleh Robbins (2013), bahwa Budaya Organisasi memiliki fungsi untuk menimbulkan komitmen organisasi pada karyawan.

Dalam beberapa penelitian yang dilakukan oleh peneliti-peneliti sebelumnya dijelaskan bahwa adanya hubungan Budaya Organisasi dengan Komitmen Organisasi seperti yang dilakukan oleh Dewi (2015) pada karyawan PT. Bank Tabungan Negara di Pekanbaru yang menunjukkan bahwa ada hubungan yang sukup baik antara dua variabel. Penelitian selanjutnya dilakukan oleh Mitić, Vukonjanski, Terek, Gligorović, dan Zorić, (2016) tentang Organizational Culture And Organizational Commitment: Serbian Case, di Republic of Serbia yang menghasilkan adanya hubungan antara dimensi pada Budaya Organisasi dengan dimensi dari Komitmen Organisasi. Kemudian penelitian oleh, Permana (2013), pada Karyawan Divisi Consumer Cards Group PT. Bank Mandiri Plaza Bapindo, menunjukkan hasil bahwa Budaya Organisasi dengan Komitmen Organisasi memiliki hubungan yang positif. Penelitian yang dilakukan oleh Hadian (2017) pada kualitas layanan publik di Bandung, menunjukkan hasil adanya hubungan yang positif dan signifikan antara Budaya Organisasi dengan Komitmen Organisasi. Selanjutnya, penelitian yang dilakukan 
sebelumnya oleh Widyastuti (2009) pada perawat Rumah Sakit Panti Wilasa Citarum, Semarang, yang menunjukkan hasil hubungan yang positif sebesar $52,2 \%$. Sedangkan dalam penelitian yang dilakukan sebelumnya oleh Nurcahya (2019) yang berjudul Hubungan antara Budaya Organisasi Dengan Komitmen Organisasi Karyawan PT. Eco Smart menunjukkan bahwa, tidak memiliki hubungan antara kedua variabel.

Penulis menemukan adanya perbedaan penelitian yang dilakukan oleh para peneliti sebelumnya dengan penelitian yang dilakukan penulis. Perbedaan tersebut nampak dari teori yang digunakan oleh penulis yang menggunakan teori milik Allen \& Meyer dan Robbins. Sedangkan peneliti-peneliti sebelumnya menggunakan teori milik Dickson et all, Gultom, Luthans, Moynihan \& Pandey, Sopiah, Muriman, Sondang Siagian. Pada metode analisis, penelitian-penelitian sebelumnya menggunakan analisis deskriptif, korelasi product moment, dan metode regresi. (Permana, 2013, Nurcahya, 2019, Widyastuti, 2009, Hadian, 2017, Dewi, 2015, Mitić et al, 2016). Penelitian ini menggunakan metode analisis deskriptif. Sementara itu, teknik pengambilan sampel, penelitian sebelumnya menggunakan metode simple random sampling, metode survei dengan teknik total sampling, purposive cluster random sampling, purposive quota sampling, cencus method, dan Globe Questionnaire. Pada kesempatan kali ini penulis menggunakan teknik quota sampling dalam pengambilan sampel. Objek penelitian dan populasi yang digunakan cukup beragam seperti, perawat Rumah Sakit Panti Wilasa Citarum, karyawan Divisi Consumer Cards Group PT. Bank Mandiri Plaza Bapindo, karyawan layanan publik, karyawan PT. Eco Smart, manajer menengah pada 129 perusahaan. (Permana, 2013, Nurcahya, 2019, Widyastuti, 2009, Hadian, 2017, Dewi, 2015, Mitić et al, 2016). Kemudian pada penelitian kali ini penulis menggunakan karyawan The Emmerick Hotel Salatiga sebagai objek penelitian.

Serangkaian penjelasan mengenai hasil-hasil penelitian terdahulu yang menunjukkan adanya pro kontra maka penulis memutuskan untuk melakukan penelitian ini bertujuan untuk melakukan kajian tentang hubungan antara Budaya Organisasi dengan Komitmen karyawan The Emmerick Hotel Salatiga yang dapat membantu pengelola hotel untuk mengetahui seberapa pentingnya penerimaan budaya organisasi karyawan untuk memiliki tingkat komitmen 
organisasi yang tinggi sehingga dapat membawa dampak baik terhadap hotel.

Berdasarkan latar belakang di atas, maka dirumuskanlah permasalahan sebagai berikut: "Apakah ada hubungan antara Budaya Organisasi dengan Komitmen Organisasi individu di The Emmerick Hotel Salatiga?"

Berdasarkan rumusan masalah yang tertera, maka tujuan penelitian ini adalah untuk menguji hubungan Budaya Organisasi terhadap Komitmen Organisasi individu di The Emmerick Hotel Salatiga.

\section{KAJIAN PUSTAKA}

Budaya organisasi yang baik memiliki hubungan dengan tingginya komitmen organisasi. Sebaliknya Budaya organisasi yang tidak baik akan memiliki hubungan yang rendah dengan komitmen organisasi yang dimiliki karyawan. Setiap organisasi memiliki budaya berupa kebiasaan atau nilai-nilai yang selalu diterapkan dalam berjalannya kegiatankegiatan pada organisasi. Dari kegiatan tersebut, terlibatnya karyawan demi kepentingan organisasinya dengan penuh usaha, dan loyalitas terhadap organisasi akan menimbulkan rasa memiliki akan organisasinya (ingin menjadi anggota tetap dalam organisasi). Apabila hal tersebut terus dilakukan maka secara otomatis akan terciptanya sebuah budaya organisasi yang mana budaya tersebut akan dapat meningkatkan komitmen organisasi setiap karyawan dan memiliki hubungan baik dengan orang-orang didalam organisasi lingkungan kerja. Pernyataan diatas dapat dipertegas karena pada dasarnya komitmen organisasi merupakan sikap karyawan yang tetarik terhadap nilai, tujuan dan target organisasi yang dapat ditunjukkan dengan adanya penerimaan karyawan atas nilai dan tujuan dari organisasi serta berkeinginan dan bersedia untuk bekerja keras demi organisasinya, sehingga demi tercapainya tujuan dan kelangsungan sebuah organisasi tersebut karyawan akan merasa betah dan tetap bertahan didalam organisasinya. Seperti yang dijelaskan oleh Robbins (1996) sebelumnya, bahwa budaya organisasi mampu membantu meningkatkan komitmen organisasi. Komitmen karyawan dapat dikembangkan dengan organisasi merekrut dan menyeleksi calon karyawan yang memiliki kecocokan dengan nilai organisasi (Teresia \& Suyasa, 2008) Adanya budaya organisasi yang dirasa cocok oleh para karyawan dapat membuat karayawan tersebut bekerja dengan maksimal, keterbukaan, kebersamaan dan kekeluargaan terhadap karywan lainya dan juga terhadap organisasi yang ditempatinya. 
Secara psikologis, karyawan yang menerima budaya organisasi yang ada di organisasi mereka bekerja, biasanya akan lebih rileks dalam bekerja, sehingga menurunkan stres yang diakibatkan karena bekerja dan merasa nyaman bekerja diorganisasinya yang membuat komitmen organisasi karyawan meningkat. Didudukung dengan penelitian yang dilakukan oleh Mohammadi \& Zarai (2016) yang mengungkapkan bahwa budaya organisasi adalah alat untuk meningkat kan komitmen organisasi karyawan karena, jika karyawan memiliki penerimaan atau kecocokan dengan budaya yang ada di organisasinya maka karyawan akan menikmati pekerjaan yang ada. Sehingga memungkinkan untuk karyawan untuk menghadapi situasi dengan stres yang lebih rendah, lebih rendah kemungkinan mengalami tegang akibat bekerja, memiliki kemampuan yang tinggi dalam menghadapi kesulitan, dan menghargai diri sendiri. Karena itu, jika karyawan memiliki kesehatan psikologis yang lebih baik dan mereka menikmatinya, maka karyawan akan memiliki komitmen yang lebih tinggi dalam organisasi.

\section{METODE PENELITIAN}

Penelitian ini dilakukan di The Emmerick Hotel Salatiga beralamat di Jl.
Raya Kopeng, Kumpulrejo, Kec. Argomulyo, Kota Salatiga, Jawa Tengah.

Partisipan dalam penelitian ini adalah 90 orang karyawan dari 100 karyawan yang ada pada The Emmerick Hotel Salatiga. Dengan menggunakan teknik sampling jenuh yaitu pengambilan sampel dimana semua anggota populasi digunakan sebagai sampel (Sugiyono, 2014).

Dalam penelitian ini, penulis menggunakan penyebaran angket yang bersifat tertutup. Menurut Yuwanto (2012) angket merupakan suatu alat ukur yang berisi sekumpulan pertanyaan atau pernyataan yang digunakan untuk mengungkap suatu variabel tertentu dalam penelitian. Kemudian ia menjelaskan bahwa angket tertutup yaitu angket yang berisi pertanyaan atau pernyataan, namun subjek memberikan jawaban atau responnya pada pilihan yang telah disediakan.

\section{Analisis Deskriptif}

Dalam menganalisa data yang diperoleh, penulis menggunakan metode deskriptif. Teknik analisis data yang digunakan adalah analisis kuantitatif yaitu analisis yang berhubungan dengan perhitungan statistic dengan menggunakan program SPSS 23. 


\section{HASIL DAN PEMBAHASAN}

Berdasarkan dari data yang telah dianalisis, maka dapat disimpulkan bahwa terdapat hubungan yang positif dan signifikan antara variabel Budaya Organisasi dan variabel Komitmen Organisasi dengan $r=0.541 ;<0,05$. Budaya organisasi mempunyai peran dalam komitmen organisasi. Artinya semakin tinggi penerimaan dan kecocokan karyawan terhadap Budaya Organisasinya maka semakin tinggi pula Komitmen Organisasi yang dimiliki karyawan. Dengan kata lain Budaya Organisasi memberi peran terhadap munculnya Komitmen Organisasi.

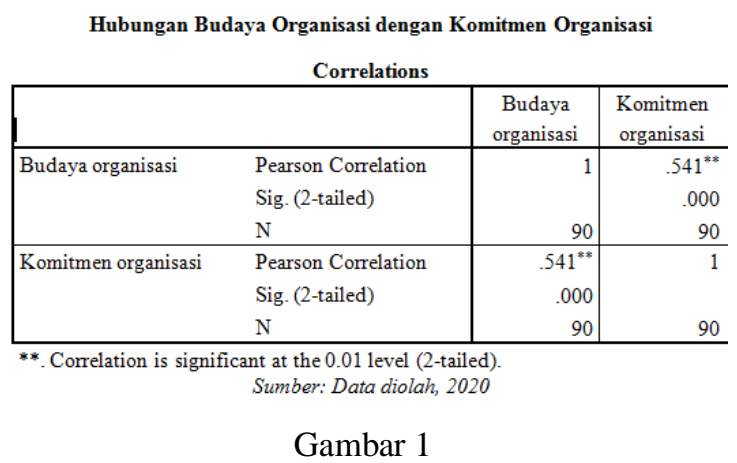

Ada beberapa kemungkinan terjadinya hubungan positif antara Budaya Organisasi dan Komitmen Organisasi. Pertama, sebagian karyawan menganggap bahwa budaya organisasi di The Emmerick Hotel Salatiga memberikan arah yang membuat mereka dapat bekerja lebih produktif dalam meningkatkan komitmen kerja. Peryataan ini didukung oleh hasil temuan Inanlou \& Ahn (2017) bahwa budaya organisasi secara langsung memengaruhi cara karyawan secara sadar berpikir, membuat keputusan, dan cara mereka memandang lingkungan di sekitar mereka. Kedua, sebagian karyawan juga menyatakan bahwa budaya organisasi tertentu memainkan peran penting dalam membentuk sikap atau perilaku mereka dalam bekerja sehingga situasi tersebut membuat karyawan dapat meningkatkan komitmen kerja mereka. Pernyataan tersebut didukung oleh temuan Mohammadi \& Zarei (2015) pada karyawan Fajr Jam Gas Refinery yang menunjukkan bahwa budaya organisasi dapat meningkatkan produktivitas karyawan yang mengarah kepada komitmen organisasi yang dimiliki oleh karyawan.

Dari data yang diperoleh rata-rata tingkat pencapaian skor budaya organisasi terletak pada interval 92-97 dan 104-109 dengan frekuensi 20 orang $(22,2 \%)$ dan tingkat kecenderungan budaya organisasi berada pada kategori tinggi sebesar $85,6 \%$ dan kategori sedang sebesar 14,4\%. Hasil ini diketahui dari 31 butir pertanyaan dengan sampel sebanyak 90 orang. Kemudian pada data yang diperoleh ratarata tingkat pencapaian skor komitmen organisasi terletak pada interval 57-62 dengan frekuensi 22 orang $(24,4 \%)$ dan tingkat kecenderungan komitmen 
organisasi berada pada kategori tinggi sebesar 24,4\%, kategori sedang sebesar $74,4 \%$ dan kategori rendah sebesar 1,1\%. Hasil ini diketahui dari 24 butir pertanyaan dengan sampel sebanyak 90 orang.

Tabel 1. Distribusi Variabel Budaya Organisasi

\begin{tabular}{|c|c|c|c|c|}
\hline kelas interval & $\mathbf{f}$ & $\mathbf{\%} \mathbf{f}$ & $\mathbf{f k}$ & \% fk \\
\hline $86-91$ & 13 & $14,4 \%$ & 13 & $14,4 \%$ \\
\hline $92-97$ & 20 & $22,2 \%$ & 33 & $36,7 \%$ \\
\hline $98-103$ & 18 & $20,0 \%$ & 51 & $56,7 \%$ \\
\hline $104-109$ & 20 & $22,2 \%$ & 71 & $78,9 \%$ \\
\hline $110-115$ & 15 & $16,7 \%$ & 86 & $95,6 \%$ \\
\hline $116-121$ & 3 & $3,3 \%$ & 89 & $98,9 \%$ \\
\hline $122-127$ & 1 & $1,1 \%$ & 90 & $100,0 \%$ \\
\hline Total & 90 & $100,0 \%$ & & \\
\hline
\end{tabular}

Dimensi pada budaya organisasi yaitu Inovasi dan pengambilan risiko, Perhatian terhadap detail, Orientasi hasil, Orientasi Individu, Orientasi Tim, Agresivitas, dan Stabilitas memiliki hubungan yang positif dan signifikan dengan komitmen organisasi. Sehingga, semakin tinggi nilai dimensi pada budaya organisasi maka akan semakin tinggi juga nilai komitmen organisasinya, begitu juga sebaliknya. Inovasi dan pengambilan risiko memiliki besar pengaruh $-0,76$ diikuti dengan Perhatian terhadap detail $14,61 \%$, Orientasi hasil 20,13\%, Orientasi Individu $-3,00 \%$, Orientasi Tim $0,81 \%$, Agresivitas 8,26\%, dan Stabilitas -2,25\%. Besar sumbangan efektif paling besar terhadap komitmen organisasi adalah dimensi orientasi hasil dengan besar pengaruh sebesar $20,13 \%$.

Tabel 2. Sumbangan Efektif dan

Korelasi Dimensi Budaya Organisasi Terhadap Komitmen Organisasi

\begin{tabular}{|c|c|c|}
\hline Dimensi & SE & Korelasi \\
\hline $\begin{array}{l}\text { Inovasi dan } \\
\text { pengambilan } \\
\text { risiko }\end{array}$ & $-0,76 \%$ & 0,256 \\
\hline $\begin{array}{l}\text { Perhatian } \\
\text { terhadap detail }\end{array}$ & $14,61 \%$ & 0,491 \\
\hline Orientasi hasil & $20,13 \%$ & 0,519 \\
\hline $\begin{array}{l}\text { Orientasi } \\
\text { individu }\end{array}$ & $-3,00 \%$ & 0,373 \\
\hline Orientasi tim & $0,81 \%$ & 0,269 \\
\hline Agresivitas & $8,26 \%$ & 0,377 \\
\hline Stabilitas & $-2,25 \%$ & 0,314 \\
\hline
\end{tabular}

Berbeda dengan hasil penelitian Dewi (2015) pada karyawan PT. Bank Tabungan Negara (Persero), Tbk Kantor Cabang Pekanbaru bahwa dimensi agresivitas menempati posisi tertinggi.

Dimensi yang terdapat dalam budaya organisasi yaitu dimensi hubungan secara individu antara inovasi dan pengambilan risiko, Orientasi individu, dan Stabilitas dengan komitmen organisasi memiliki nilai yang positif dan signifikan. Dapat disimpulkan bahwa budaya organisasi yang berjalan di The Emmerick Hotel Salatiga berjalan dengan baik dan efisien sehingga dimensi yang ada menunjukkan hasil yang posiyif serta signifikan terhadap komitmen organisasi. 
Berhubungan dengan kedua hal tersebut, budaya organisasi akan memberikan dampak kepuasan organisasi yang di rasakan oleh karyawan baik yang berasal dari dalam dirinya maupun berasal dari luar diri karyawan tersebut akan menentukan tingkat komitmen organisasi karyawan. Hasil pengujian membuktikan bahwa budaya organisasi berhubungan signifikan pada komitmen organisasi karyawan di The Emmerick Hotel Salatiga dengan perolehan nilai sebesar $54,1 \%$.

Pada penelitian ini juga penulis menemukan hubungan demografi dengan komitmen organisasi karyawan. Ditemukan bahwa karyawan laki-laki berusia 26-35 tahun memiliki komitmen yang tinggi dibandingkan dengan karyawan perembuan berusia sama. Ini dibuktikan dari lama mereka bekerja yaitu sekitar 4-7 tahun.

\section{PENUTUP}

\section{Kesimpulan}

1. Terdapat hubungan positif dan signifikan antara budaya organisasi dengan komitmen organisasi pada karyawan The Emmerick Hotel Salatiga.

2. Besar sumbangan efektif dimensi pada budaya organisasi terhadap komitmen organisasi yang terbesar merupakan dimensi orientasi hasil, diikuti dengan dimensi perhatian terhadap detail, dimensi agresivitas, dimensi orientasi tim, dimensi inovasi, dimensi pengambilan risiko, dimensi stabilitas dan yang terakhir adalah dimensi orientasi.

\section{Saran}

\section{Pihak Manajemen}

Pihak manajemen diharapkan dapat mempertahankan serta meningkatkan penanaman nilai-nilai budaya organisasi kepada setiap karyawan di dalam organisasi terebut. memberikan contoh yang teladan bagi setiap karyawan dalam menjalankan budaya organisasi, sehingga dapat terus meningkatkan komitmen organisasi pada setiap karyawan. Ada beberapa cara yang dapat dilakukan seperti menjunjung tinggi nialai-nilai kejujuran, kedisiplinan, tanggung jawab melalui diskusi atau sharing dengan atasan dan koleganya.

2. Bagi pihak karyawan

Setiap karyawan memiliki kesempatan yang sama dalam mengamalkan nilai-nilai budaya organisasi yang sudah terbentuk untuk meningkatkan komitmennya terhadap oragnisasi dalam mendukung tugas serta tanggung jawabnya. Ada beberapa cara yang dapat digunakan misalnya sharing atau diskusi dan mengaplikasikan berbagai nilai budaya yang sudah dijalankan dalam organisasi tersebut melalui sikap jujur, sopan santun,, dan 
tanggung jawab ketika berhadapan dengan atasan, kolega dan para pengguna jasa.

3. Bagi peneliti selanjutnya,

Setiap peneliti disarankan untuk dapat melakukan pengembangan penelitian. Misalnya dengan meneiliti variabel bebas lain yang dapat mempengaruhi komitmen organisasi pada karyawan seperti, motivasi, kemampuan karyawan dan lain sebagainya. Atau dengan menggunakan metode penelitian yang berbeda.

\section{DAFTAR PUSTAKA}

Dewi, S., (2015). Hubungan Budaya Organisasi dengan Komitmen Organisasi pada PT. Bank Tabungan Negara (Persero), Tbk Kantor Cabang Pekanbaru. JOM FISIP, 2 (2), 1-12.

Emiroğlua, B., D., et al. (2015). The Relationship Between Turnover Intention and Demographic Factors in Hotel Businesses: A Study at Five Star Hotels In Istanbul. Procedia - Social and Behavioral Science,s 207, 385 397.

Gultom, D., K. (2014). Pengaruh Budaya Perusahaan Dan Motivasi Terhadap Kinerja Karyawan PT. Perusahaan gas negara (persero) Tbk. Medan. Jurnal Manajemen \& Bisnis, 14 (2), 176-184.

Inanlou, Z. \& Ahn, J. (2017). The Effect Of Organizational Culture On Employee Commitment: A Mediating Role Of Human Resource Development In Korean Firms. The Journal of Applied Business Research, 33 (1), 87-94.
Khan, A., \& Turowski, K. (2016). A Survey of Current Challenges in Manufacturing Industry and Preparation for Industry 4.0. Paper presented at the Proceedings of the First International Scientific Conference "Intelligent Information Technologies for Industry"(IITI'16). Springer International Publishing Switzerland, 1 (2) 15-26.

Mitić S., Vukonjanski J., Terek E., Gligorović B., Zorić K., (2016). Organizational Culture and Organizational Commitment: Serbian Case. Republic of Serbia: University of Novi Sad. Journal Of Engineering Management And Competitiveness (Jemc), 6 (1), 21 27.

Meyer, J. P. \& Allen, N. (1990). The Measurement and Antecendents of Affective, Continuance and Normative Commitment to The Organization. Journal of accupational Psychology, 63, 1-8.

Mulyaningsih. (2016). Analisis FaktorFaktor yang Mempengaruhi Komitmen Kerja Karyawan (Studi pada Karyawan Batik Brotoseno Sragen). Skripsi. Kota Surakarta: Universitas Muhammadiyah Surakarta.

Mohammadi, Z. \& Zarei, R. (2015). The Relationship between Organizational Culture and Organizational Commitment by Benefiting by Fajr Jam Refinery. Special Issue on New Dimensions in Economics, Accounting and Management, 4 (1), 1672-1680.

Nurcahya, T., (2019). Hubungan Antara Budaya Organisasi dengan 
Komitmen Organisasi Karyawan PT. Eco Smart. Skripsi. Solo: Universitas Muhammadiyah Surakarta

Prasetyo, B. \& Trisyanti, U. (2018). Revolusi Industri 4.0 dan Tantangan Perubahan Sosial. Prosiding SEMATEKSOS 3 "Strategi Pembangunan Nasional MenghadapiRevolusiIndustri 4.0", 22-27.

Robbins, Stephen P. \& Judge, Timothy, A. (2013) Organizational Commitment Behavior Edition 15. New Jersey: Pearson Education. 511-541.

Sapril (2011). Komunikasi Interpersonal Pustakawan. Jurnal Iqra 05 (01), 6-11.

Situmorang, B. (2014). Faktor-Faktor Penentu Komitmen Organisasi Kepala SMK (Studi Kasus pada SMK di Kota Medan). Cakrawala Pendidikan, 2 (1), 39-49.

Subagyo, S., Akbar, M., Wibowo, (2019).

The Effect of Leadership,
Adversity Quotient on Organizational Commitment of PT. Jaya Konstruksi Manggala Pratama Tbk. IJEBD : (International Journal of Entrepreneurship and Business Development), 2 (2), 271-279.

Sugiyono. (2014). Metode Pemelitian Pendidikan Pendekatan Kuantitatif, Kualitatif, dan R\&D. Bandung: Alfabeta. 24-25.

Tazkia, H., (2017). Hubungan Antara Budaya Organisasi dengan Komitmen Kerja Guru di MTS Negeri 2 Medan. Skripsi. Medan: Universitas Islam Negeri.

Widyastuti, H. C., (2009). Hubungan Antara Budaya Organisasi Dengan Komitmen Organisasi pada Perawat Rumah Sakit Panti Wilasa Citarum. Skripsi. Semarang: UNDIP.

Yuwanto, L. (2012). Pengantar Metode Penelitian Eksperimen. Dwiputra Pustaka Jaya: Jakarta. 34-36. 